\title{
Keefektifan Allelopati Teki (Cyperus rotundus L.) terhadap Penekanan Perkecambahan Biji Asystasia gangetica (L.) T. Anderson pada Berbagai Jenis Tanah
}

\author{
Efectivity Nutsedge Allelophatic (Cyperus rotundus L.) to suppress Asystasia gangetica (L.) T. Anderson \\ Seed Germination on Some Soil Types
}

\author{
Martika Andhini dan MA Chozin*
}

Departemen Agronomi dan Hortikultura, Fakultas Pertanian, Institut Pertanian Bogor (Bogor Agricultural University), Jl. Meranti, Kampus IPB Darmaga, Bogor 16680, Indonesia Telp. \& Faks.62-251-8629353 e-mail agronipb@indo.net.id

*Penulis korespondensi: ma_chozin@yahoo.com

Disetujui 4 Mei 2016/ Published online 9 Mei 2016

\begin{abstract}
Some previous research indicated that allelophatic in nutsedge (Cyperus rotundus) has potential to be used as bioherbicide to suppress broadleaf weed seed germination. The aim of this research was to know the effect of various formulations nutsedge biomass in suppresing Asystasia gangetica germination, which is a serious problem in many plantation. Another purpose of this research was to know effect of different concentration of extract nutsedge to suppressing seed germination of A. gangetica on some types of soil. This research was conducted in Juni-October 2014 in Ecofisiology Plant Laboratory, Agronomy and Horticulture Department. The first experiment using a randomized complete design with 5 treatments formulation nutsedge biomass, these are fresh nutsedge, dried nutsedge, granule, powder and control. The second treatment using factorial randomized complete design with treatment of the extract concentration nutsedge $0 \mathrm{~kg} \mathrm{~L}^{-1}, 1 \mathrm{~kg} \mathrm{~L}^{-1}, 2 \mathrm{~kg} \mathrm{~L}^{-1}$, dan $3 \mathrm{~kg} \mathrm{~L}^{-1}$ and type soils treatment with different clay composition (kuarsa, regosol, andosol, latosol and podsolik). All treatment were conducted in 3 replicates. Result of this research show that all formulation of nutsedge effectively suppress A. gangetica seed germination compared with control. The type of soil gives significant effect on the suppresion of germination A. gangetica seed. In all types of soil application of nutsedge extract showed a tendency that higher concentration of nutsedge extract, higher pressing A. gangetica seed germination.
\end{abstract}

Keywords: allelophatic, bioherbicide, concentration, formulation

\section{ABSTRAK}

Beberapa penelitian terdahulu mengindikasikan bahwa allelopati pada teki (Cyperus rotundus) berpotensi untuk dimanfaatkan sebagai bioherbisida untuk menekan perkecambahan biji gulma berdaun lebar. Penelitian ini bertujuan untuk mengetahui pengaruh berbagai formulasi biomassa teki dalam menekan perkecambahan biji gulma Asystasia gangetica, gulma berdaun lebar yang menjadi masalah di berbagai perkebunan. Tujuan lain dari penelitian ini adalah untuk mengetahui pengaruh perbedaan konsentrasi ekstrak teki dalam menekan perkecambahan biji A. gangetica pada berbagai jenis tanah. Penelitian dilaksanakan pada bulan Juni-Oktober 2014 di Laboratorium Ekofisiologi Tanaman, Departemen Agronomi dan Hortikultura. Percobaan pertama menggunakan Rancangan Acak Lengkap (RAL) dengan perlakuan 5 formulasi biomassa teki yaitu mulsa basah, mulsa kering, butiran, tepung, dan kontrol. Percobaan kedua menggunakan Rancangan Acak Lengkap (RAL) faktorial dengan

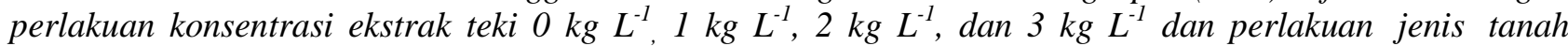
dengan perbedaan kandungan liat yaitu kuarsa, regosol, andosol, latosol dan podsolik. Seluruh perlakuan diulang 3 kali. Hasil penelitian menunjukkan bahwa seluruh formulasi teki yang diuji secara nyata efektif menekan perkecambahan biji gulma A. gangetica dibandingkan dengan kontrol. Jenis tanah sangat nyata mempengaruhi persentase perkecambahan biji A. gangetica. Aplikasi ekstrak teki menunjukkan kecendrungan semakin tinggi pada semua jenis tanah konsentrasi ekstrak teki semakin menekan perkecambahan biji A. gangetica.

Kata kunci: allelopati, bioherbisida, formulasi, konsentrasi 


\section{PENDAHULUAN}

Beberapa tahun terakhir, banyak penelitian dan kajian tentang allelopati yang bertujuan untuk mendukung teknologi budidaya tanaman ramah lingkungan pada sistem tanaman yang berkelanjutan. Allelopati adalah senyawa kimiawi yang dihasilkan oleh tumbuhan pada waktu hidup maupun setelah mati (bagian-bagian yang busuk) yang mempengaruhi tumbuhan lain yang tumbuh disekitarnya (Sastrautomo, 1990). Umumnya, allelopati berupa metabolit sekunder yang terdapat dalam organ-organ seperti akar, daun, batang, bunga dan biji. Allelopati dikeluarkan dalam bentuk eksudat dari akar, serbuk sari, luruhan organ dan senyawa yang menguap dari organ-organ gulma ataupun tanaman.

Teki (Cyperus rotundus L.) merupakan salah satu gulma penting yang menyebar secara luas di seluruh daerah tropis dan subtropis. Teki merupakan salah satu dari kelompok gulma berbahaya. Gulma ini menjadi masalah yang serius karena mempunyai kemampuan yang dapat tumbuh pada berbagai jenis tanah dan suhu tinggi. Selain itu juga dapat menurunkan produksi secara nyata pada beberapa komoditas pangan seperti jagung, padi dan kedelai (Moenandir, 2010). Hasil penelitian Inawati (2000) menunjukkan kehadiran gulma $C$. rotundus pada lahan kedelai dapat menurunkan produksi sebesar $37 \%$. Penurunan produksi tersebut disebabkan oleh kompetisi terhadap sumberdaya, allelopati atau kombinasi dari keduanya.

Allelopati dari $C$. rotundus tidak hanya menekan pertumbuhan dan produksi tanaman pangan, tapi juga dapat menekan pertumbuhan gulma lain. Saputra (2012) menyatakan bahwa biomassa teki ( $C$. rotundus) dapat digunakan untuk menekan pertumbuhan gulma daun lebar. Ekstrak $C$. rotundus dapat menekan perkecambahan beberapa gulma berdaun lebar dengan berbagai konsentrasi pada skala laboratorium (Delsi, 2012). Salah satu gulma berdaun lebar yang dapat ditekan perkecambahannya dengan ekstrak teki adalah Asystasia gangetica (L) T. Enderson. A.gangetica adalah gulma utama di kebun kelapa sawit. Menurut (Mubarok, 2010) A. gangetica menutupi lahan kelapa sawit sebesar $16.36 \%$.

Keefektifan herbisida dalam tanah dipengaruhi oleh proses adsorpsi tanah. Adsorpsi herbisida oleh partikel tanah akan menyebabkan herbisida tersebut berkurang keefektifannya. Tanah dengan kandungan liat tinggi memiliki kemampuan adsorpsi lebih kuat dibandingkan tanah dengan kandungan liat yang lebih rendah.
Hal tersebut dibuktikan dalam penelitian Muktamar et al. (2003) yang menunjukkan bahwa tanah dengan kandungan liat lebih tinggi mengadsorpsi lebih banyak unsur-unsur yang masuk ke tanah, Wardoyo et al. (2011) menambahkan bahwa penyebaran herbisida dalam tanah sangat ditentukan oleh kadar liat dalam tanah.

Berdasarkan serangkaian penelitiannya, Chozin et al. (2013) menyatakan C. rotundus efektif menekan perkecambahan biji gulma berdaun lebar dan berpotensi untuk dikembangkan sebagai bioherbisida pre emergence. Untuk mengetahui keefektifan dalam menekan perkecambahan gulma, perlu dilakukan penelitian yang terkait dengan aplikasinya di lapang seperti konsentrasi, formulasi, waktu aplikasi serta kondisi lapang termasuk jenis tanah. Tujuan dari penelitian ini adalah untuk mengetahui keefektifan allelopati teki terhadap penekanan perkecambahan biji gulma $A$. gangetica, gulma utama di perkebunan kelapa sawit.

Tujuan umum penelitian ini adalah mengetahui keefektifan allelopati teki terhadap perkecambahan biji gulma A. gangetica. Sedangkan tujuan khusus penelitian adalah mengetahui efektifitas berbagai formulasi biomassa teki untuk menekan perkecambahan $A$. gangetica dan mengetahui keefektifan berbagai konsentrasi ektrak teki terhadap perkecambahan gulma A. gangetica pada berbagai jenis tanah.

\section{METODE PENELITIAN}

Percobaan dilaksanakan pada bulan Juni sampai bulan Oktober 2014 di Laboratorium Ekofisiologi Tanaman, Departemen Agronomi dan Hortikultura, Fakultas Pertanian, Institut Pertanian Bogor. Sterilisasi tanah dilakukan di Laboratorium Bioteknologi Tanah, Departemen Ilmu dan Manajemen Sumberdaya Tanah, Fakultas Pertanian, Institut Pertanian Bogor.

Bahan yang digunakan terdiri atas teki segar, biji gulma Asystasia gangetica, air, 5 jenis tanah yaitu podsolik, kuarsa, regosol, latosol dan andosol. Bahan lain yang digunakan adalah tepung kanji. Peralatan yang digunakan antara lain : sprayer, wadah berukuran $15 \mathrm{~cm}$ x $20 \mathrm{~cm}$ x $5 \mathrm{~cm}$, blender, autoklaf dan alat tulis.

Penelitian ini terdiri atas 2 percobaan, sebagai berikut :

1. Efektifitas Berbagai Macam Formulasi Biomassa Teki terhadap Biji Gulma $A$. gangetica

Percobaan ini disusun menggunakan rancangan acak lengkap (RAL) dengan 3 ulangan 
dan 5 perlakuan. Perlakuan yang diuji adalah kontrol (air), tepung, butiran, mulsa basah dan mulsa kering. Biji gulma dikecambahkan pada wadah yang berukuran $15 \mathrm{~cm} \times 20 \mathrm{~cm}$ yang telah diisi tanah. Setiap wadah dikecambahkan 25 biji gulma.

Formulasi pada percobaan ini terdiri atas 4 formulasi yaitu mulsa basah, mulsa kering, tepung dan butiran. Mulsa basah didapatkan dari teki segar yang diambil dari lapang. Selanjutnya dibersihkan dari tanah dan kotoran yang menempel menggunakan air. Setelah itu dikering anginkan, dipotong-potong dan ditimbang $43.20 \mathrm{~g}$ teki basah per $0.30 \mathrm{~m}^{2}$. Mulsa kering didapatkan dari mulsa basah yang ditimbang $43.20 \mathrm{~g}$ teki basah per $0.30 \mathrm{~m}^{2}$, selanjutnya dioven selama 3 hari pada suhu $60{ }^{\circ} \mathrm{C}$. Pembuatan formulasi tepung teki dibuat dari mulsa kering yang dihaluskan menggunakan blender. Butiran biomassa teki dibuat menggunakan tepung teki yang dicampur dengan tepung kanji. Tepung teki ditaburkan dalam wadah, kemudian disemprot dengan larutan kanji. Setelah itu diaduk-aduk dan dibentuk menjadi bulatan-bulatan kecil.

Biji A. gangetica dikecambahkan dalam wadah yang berukuran $15 \mathrm{~cm} \times 20 \mathrm{~cm} \times 5 \mathrm{~cm}$ yang telah diisi dengan tanah. Setiap nampan diisi tanah dengan ketinggian $3 \mathrm{~cm}$. Biji A. gangetica ditanam dengan jarak tanam $4 \mathrm{~cm} \mathrm{x} 3 \mathrm{~cm}$, sehingga terdapat 25 biji $A$. gangetica dalam setiap wadah. Setelah dikecambahkan, aplikasi formulasi biomassa $C$. rotundus dilakukan dengan cara menebarkan ke permukaan tanah secara merata. Kegiatan pemeliharaan adalah menjaga kelembaban tanah dengan menyemprot permukaan tanah dengan air secukupnya menggunakan sprayer kecil setiap hari.

\section{Efektifitas Berbagai Konsentrasi Ekstrak Teki pada Berbagai Jenis Tanah \\ Rancangan lingkungan yang digunakan} untuk percobaan ini adalah rancangan acak lengkap (RAL) faktorial 2 faktor yang terdiri atas faktor perbedaan jenis tanah dan konsentrasi ekstrak $C$. rotundus. Jenis tanah yang digunakan adalah kuarsa, regosol, latosol, andosol dan podsolik. Konsentrasi teki yang digunakan adalah $0 \mathrm{~kg} \mathrm{~L}^{-1}, 1 \mathrm{~kg} \mathrm{~L}^{-1}, 2 \mathrm{~kg} \mathrm{~L}^{-1}$ dan $3 \mathrm{~kg} \mathrm{~L}^{-1}$. Semua perlakuan diulang 3 kali.

Langkah awal yang dilakukan pada percobaan kedua ini adalah sterilisasi tanah. Tanah dibersihkan dengan membuang kotoran dan disterilkan dengan menggunakan autoklaf. Sterilisasi dilakukan berdasarkan metode yang digunakan Cahyani (2009). Sterilisasi bertujuan agar tanah terhindar dari benih-benih gulma lainnya. Sebelum dimasukkan autoklaf, tanah dimasukkan ke dalam plastik agar tidak tercecer ketika dimasukkan ke dalam autoklaf. Tanah disterilkan dalam autoklaf dengan suhu $150{ }^{\circ} \mathrm{C}$ selama 20 menit dengan 3 kali ulangan. Selanjutnya tanah yang sudah disterilkan diisikan ke dalam nampan plastik yang berukuran $15 \mathrm{~cm} \mathrm{x}$ $20 \mathrm{~cm} \times 5 \mathrm{~cm}$. Setiap nampan diisi dengan tanah hingga ketinggian $3 \mathrm{~cm}$. Benih dikecambahkan dengan cara dimasukkan sedikit ke dalam tanah kurang lebih dengan kedalaman $0.5 \mathrm{~cm}$.

Langkah selanjutnya adalah ekstraksi teki.

C. rotundus yang diambil dari lapangan dibersihkan dari tanah-tanah yang menempel agar bersih dari gulma dan kotoran lainnya. Ekstraksi dilakukan berdasarkan metode yang dilakukan oleh Delsi (2012). Untuk membuat konsentrasi teki $1 \mathrm{~kg} \mathrm{~L}^{-1}$, biomassa teki sebanyak $1 \mathrm{~kg}$ dihaluskan menggunakan blender kemudian ditambahkan aquades sebanyak 1 L dan didiamkan selama \pm 24 jam. Ekstrak tersebut kemudian diperas dan disaring, begitu selanjutnya

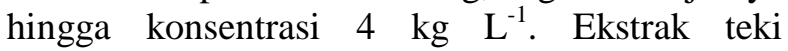
dimasukkan dalam alat semprot yaitu sprayer. Sprayer diisi dengan masing-masing konsentrasi. Ekstrak disemprot ke nampan plastik yang telah ditanami gulma. Pengamatan yang dilakukan pada percobaan 1 dan percobaan 2 ini adalah pertumbuhan kecambah selama 30 hari. Parameter pengamatannya adalah jumlah kecambah normal, persentase perkecambahan, daya berkecambah dan kecepatan tumbuh. Penghitungan kecepatan tumbuh dilakukan dengan pengamatan setiap hari sehingga mendapatkan presentase tumbuh.

Data yang diperoleh dianalisis dengan sidik ragam (Uji F). Apabila menunjukkan pengaruh nyata dilakukan uji lanjut Duncan's Multiple Range Test (DMRT) pada taraf 5\%.

\section{HASIL DAN PEMBAHASAN}

\section{Percobaan 1 Efektifitas Berbagai Formulasi Biomassa Teki terhadap Biji A. gangetica}

Percobaan 1 bertujuan mengetahui efektifitas berbagai formulasi biomassa teki untuk menekan perkecambahan biji A. gangetica. Formulasi yang digunakan dalam percobaan ini adalah kontrol (air), mulsa basah, mulsa kering, butiran dan tepung. Hasil sidik ragam menunjukkan bahwa formulasi biomassa teki berpengaruh nyata terhadap persentase perkecambahan biji gulma $A$. gangetica, tetapi tidak berpengaruh nyata terhadap persentase kecambah tidak normal dan kecepatan kecambah. Tabel 1 tersebut menunjukkan semua formulasi sangat nyata menekan biji A. gangetica berkisar 
$70 \%-100 \%$ dibandingkan dengan kontrol. Hal itu memperkuat dugaan allelopati teki masih dapat digunakan walaupun teki telah dikeringkan. Hasil pada percobaan 1 memperkuat dugaan bahwa teki dapat digunakan sebagai bioherbisida, penekanan tertinggi diperoleh pada perlakuan butiran (0\%), tepung $(2.70 \%)$ dan mulsa basah $(2.70 \%)$.

Tabel 1. Rata-rata perkecambahan, kecepatan tumbuh dan kecambah tidak normal biji A. gangetica pada berbagai perlakuan formulasi teki

\begin{tabular}{lcll}
\hline Perlakuan & $\begin{array}{c}\text { Perkecambahan } \\
(\%)\end{array}$ & $\begin{array}{c}\text { Kecambah } \\
\text { tidak } \\
\text { Normal }(\%)\end{array}$ & $\begin{array}{c}\text { KCT } \\
(\%\end{array}$ \\
\hline etmal & $-1)$ \\
Mulsa basah & $2.70 \mathrm{~b}$ & 0.03 & 0.01 \\
Butsa kering & $14.70 \mathrm{~b}$ & 0.09 & 0.01 \\
Tepung & $0.00 \mathrm{~b}$ & 0.00 & 0.00 \\
Kontrol & $2.70 \mathrm{~b}$ & 0.20 & 0.02 \\
\hline
\end{tabular}

Angka yang dikuti huruf yang sama pada kolom yang sama tidak berbeda nyata menurut uji DMRT 5\%

Biomassa teki dalam bentuk tepung, butiran dan mulsa basah akan lebih mudah dan murah. Keuntungan penggunaan herbisida dalam bentuk butiran lebih efektif dalam penyebaran herbisida karena ketika aplikasi cenderung langsung sampai ke tanah (Moenandir 2010). Sementara menurut Cobb dan Reade (2010) keuntungan penggunaan herbisida dalam bentuk tepung adalah mudah untuk diaplikasikan dan mudah dalam pembuatannya. Selain itu, teki dalam bentuk tepung dapat disimpan untuk waktu yang lama, sehingga mempermudah untuk pengaplikasian. Untuk memperoleh informasi tentang keefektifan penggunaannya di lapangan perlu dilakukan percobaan di lapangan.

\section{Percobaan 2 Efektifitas Berbagai Konsentrasi Ekstrak Teki pada Berbagai Jenis Tanah}

Percobaan 2 bertujuan mengetahui keefektifan berbagai konsentrasi ekstrak teki terhadap perkecambahan biji gulma A. gangetica pada berbagai jenis tanah. Tanah-tanah tersebut memiliki tekstur yang berbeda (Tabel 2). Tekstur tanah dapat mempengaruhi sirkulasi air dan udara.

Tekstur tanah dapat mempengaruhi perkecambahan biji A. gangetica. Tanah yang didominasi pasir menyebabkan air dan udara mudah keluar-masuk (Hanafiah 2007). Anas dan Tampubolon (2004) juga menambahkan bahwa tanah yang dicampur dengan pasir memiliki sirkulasi udara yang baik.
Tabel 2. Analisis kandungan pasir, debu dan liat pada beberapa jenis tanah

\begin{tabular}{lccc}
\hline $\begin{array}{l}\text { Jenis } \\
\text { tanah }\end{array}$ & $\begin{array}{c}\text { Pasir } \\
(\%)\end{array}$ & $\begin{array}{l}\text { Debu } \\
(\%)\end{array}$ & $\begin{array}{c}\text { Liat } \\
(\%)\end{array}$ \\
\hline Kuarsa & 98.29 & 0.65 & 1.06 \\
Regosol & 64.14 & 16.47 & 10.39 \\
Andosol & 31.92 & 22.89 & 45.19 \\
Latosol & 9.27 & 24.62 & 66.11 \\
Podsolik & 11.21 & 13.07 & 75.76 \\
\hline
\end{tabular}

Sumber : Laboratorium Kimia Tanah Departemen Ilmu Tanah dan Sumberdaya Lahan Fakultas Pertanian IPB 2014

Hasil sidik ragam menunjukkan bahwa konsentrasi ekstrak teki berpengaruh sangat nyata terhadap kecambah tidak normal tetapi tidak berpengaruh nyata terhadap perkecambahan dan kecepatan tumbuh. Jenis tanah berpengaruh sangat nyata terhadap perkecambahan tetapi tidak berpengaruh nyata terhadap kecambah tidak normal dan kecepatan tumbuh. Interaksi antara konsentrasi ekstrak teki dengan jenis tanah pada Tabel 3 tidak berpengaruh nyata terhadap perkecambahan, kecambah normal dan kecepatan tumbuh.

Tabel 3. Rekapitulasi sidik ragam pengaruh konsentrasi ekstrak $C$. rotundus dan jenis tanah terhadap perkecambahan biji A.gangetica

\begin{tabular}{|c|c|c|c|}
\hline Parameter & Konsentrasi & $\begin{array}{l}\text { Jenis } \\
\text { tanah }\end{array}$ & Interaksi \\
\hline Perkecambahan (\%) & $0.88^{\mathrm{tn}}$ & $0.002^{* * *}$ & $0.42^{\mathrm{tn}}$ \\
\hline $\begin{array}{l}\text { Kecambah tidak } \\
\text { normal }(\%)\end{array}$ & $0.007^{* *}$ & $0.32^{\mathrm{tn}}$ & $0.42^{\mathrm{tn}}$ \\
\hline $\begin{array}{l}\text { Kecepatan tumbuh } \\
\left(\% \text { etmal }^{-1}\right)\end{array}$ & $0.31^{\text {tn }}$ & $0.06^{\mathrm{tn}}$ & $0.08^{\operatorname{tn}}$ \\
\hline
\end{tabular}

Hasil percobaan yang disajikan pada Tabel 4 menunjukkan bahwa peningkatan konsentrasi ekstrak teki nyata meningkatkan kecambah tidak normal. Kecambah tidak normal pada konsentrasi $0 \mathrm{~kg} \mathrm{~L}^{-1}$ sebesar $0 \%$, lebih rendah dibandingkan dengan konsentasi $1 \mathrm{~kg} \mathrm{~L}^{-1}$, $2 \mathrm{~kg} \mathrm{~L}^{-1}, 3 \mathrm{~kg} \mathrm{~L}^{-1}$ dengan persentase kecambah tidak normal berturut-turut sebesar $14.73 \%$, $19.20 \%$ dan $28.73 \%$. Meningkatnya kecambah $A$. gangetica tidak normal diduga karena efek allelopati dari ekstrak teki menghambat perkecambahan.

Perbedaan konsentrasi menunjukkan hasil yang tidak berbeda nyata dalam menekan perkecambahan biji gulma A. gangetica. Meskipun demikian, aplikasi ekstrak teki mampu menekan persentase perkecambahan seiring meningkatnya konsentrasi ekstrak teki yang diberikan. Pada konsentrasi $0 \mathrm{~kg} \mathrm{~L}^{-1}$ persentase 
kecambah adalah $49.87 \%$, sedangkan pada konsentrasi $1 \mathrm{~kg} \mathrm{~L}^{-1}$ biji A. gangetica mengalami penekanan perkecambahan hingga persentase kecambah sebesar $44.80 \%$. Konsentrasi $2 \mathrm{~kg} \mathrm{~L}^{-1}$ ekstrak teki mampu menekan perkecambahan hingga persentase kecambah sebesar $36.80 \%$ dan aplikasi konsentrasi $3 \mathrm{~kg} \mathrm{~L}^{-1}$ persentase kecambah A. gangetica $37.60 \%$.

Tabel 4. Rata-rata perkecambahan, kecambah tidak normal dan kecepatan kecambah pada perlakuan konsentrasi ekstrak teki dan jenis tanah

\begin{tabular}{lccc}
\hline Perlakuan & $\begin{array}{c}\text { Perkecambahan } \\
(\%)\end{array}$ & $\begin{array}{c}\text { Kecambah } \\
\text { tidak } \\
\text { normal } \\
(\%)\end{array}$ & $\begin{array}{c}\text { Kecepatan } \\
\text { kecambah } \\
\left(\% \text { etmal }^{-1}\right)\end{array}$ \\
\hline Konsentrasi & 49.87 & & \\
$0 \mathrm{~kg} \mathrm{l}^{-1}$ & 44.80 & $0.00 \mathrm{~b}$ & 1.7 \\
$1 \mathrm{~kg} \mathrm{l}^{-1}$ & 36.80 & $14.73 \mathrm{a}$ & 1.7 \\
$2 \mathrm{~kg} \mathrm{l}^{-1}$ & 37.60 & $19.20 \mathrm{a}$ & 1.6 \\
$3 \mathrm{~kg} \mathrm{l}^{-1}$ & & $28.73 \mathrm{a}$ & 1.4 \\
\hline Jenis tanah & & & \\
Kuarsa & $14.00 \mathrm{~d}$ & 3.75 & 0.4 \\
Regosol & $75.33 \mathrm{a}$ & 20.42 & 1.0 \\
Andosol & $54.33 \mathrm{~b}$ & 20.67 & 1.7 \\
Latosol & $26.33 \mathrm{~cd}$ & 14.00 & 0.4 \\
Podsolik & $41.33 \mathrm{bc}$ & 19.50 & 2.0 \\
\hline Angkatang & & &
\end{tabular}

Angka yang diikuti huruf yang sama pada kolom yang sama tidak berbeda nyata menurut uji DMRT 5\%

Hasil percobaan juga menunjukkan bahwa jenis tanah berpengaruh nyata terhadap perkecambahan biji A. gangetica (Tabel 4). Nilai perkecambahan tertinggi terdapat pada biji A. gangetica yang ditanam pada tanah regosol, andosol, podsolik, latosol dan kuarsa dengan nilai perkecambahan berturut-turut yaitu $75 \%, 54 \%$, $41 \%, 26 \%$ dan $14 \%$. Perbedaan kandungan pasir, liat dan debu dalam tanah menyebabkan sirkulasi udara dan air serta adsorpsi juga berbeda.

Perkecambahan paling tinggi pada konsentrasi K1 terlihat pada perlakuan jenis tanah regosol yaitu $76 \%$, sedangkan pada jenis tanah andosol, podsolik, latosol dan kuarsa adalah 69\%, $48 \%$, 29\% dan 24\%. Gambar 1 menunjukkan perkecambahan gulma pada semua jenis tanah menunjukkan kecenderungan yang sama yaitu semakin tinggi konsentrasi ekstrak teki yang diberikan, semakin menekan perkecambahan biji gulma $A$. gangetica.

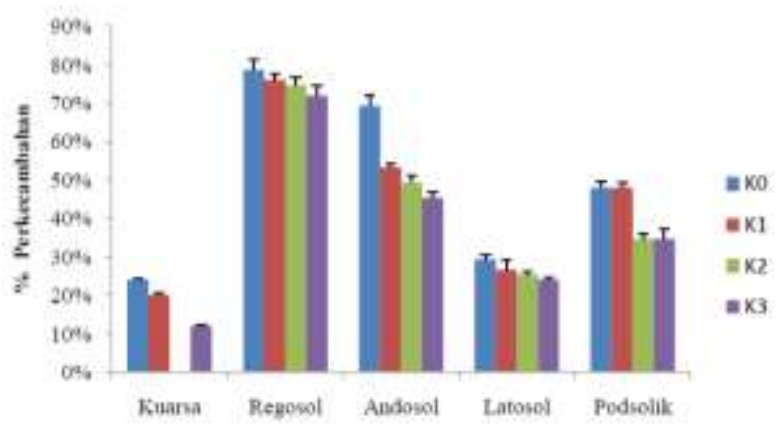

Gambar 1. Persentase kecambah A. gangetica pada berbagai konsentrasi terhadap berbagai jenis tanah

Ekstrak teki yang diaplikasikan pada tanah dengan persentase pasir tinggi yaitu kuarsa di percobaan ini didapatkan hasil perkecambahan yang rendah dibandingkan dengan tanah jenis lain. Adsorpsi ekstrak teki oleh liat tanah dapat menyebabkan ekstrak tersebut kurang efektif dalam mengendalikan gulma. Hal tersebut sesuai dengan penelitian Muktamar et al. (2003) yang menyatakan bahwa perilaku herbisida dipengaruhi oleh adsorpsi koloid tanah. Kandungan liat yang tinggi diduga secara langsung mempengaruhi perkecambahan bagi gulma karena kurang sirkulasi udara dan air yang penting untuk perkecambahan biji, serta mempengaruhi keefektifan ekstrak teki dalam menekan perkecambahan. Standar deviasi pada Gambar 1 menunjukkan bahwa pemberian konsentrasi teki yang berbeda menunjukkan kecenderungan yang sama yaitu menekan perkecambahan biji gulma, sehingga dengan pengaplikasian dengan konsentrasi $1 \mathrm{~kg} \mathrm{~L}^{-1}$ sudah efektif menekan perkecambahan.

Pada tanah andosol, tidak ada kecambah tidak normal pada K0, sedangkan pada K1 sebanyak 23\% kecambah yang tidak tumbuh secara normal (Gambar 2). Pada konsentrasi K2 naik sebesar $2 \%$ apabila dibandingkan dengan K1. Pada K3, kecambah tidak normal 35\%. Biji yang ditanam di tanah yang lain juga menunjukkan persentase kecambah tidak normal yang tinggi pada ekstrak $C$. rotundus dengan konsentrasi $3 \mathrm{~kg} \mathrm{~L}^{-1}$. Kecambah yang tidak normal diduga karena efek allelopati dari $C$. rotundus. Hal tersebut konsisten dengan Gambar 1 dan menguatkan penelitian Delsi (2012) yang menyatakan bahwa ekstrak $C$. rotundus dapat menurunkan perkecambahan gulma. 


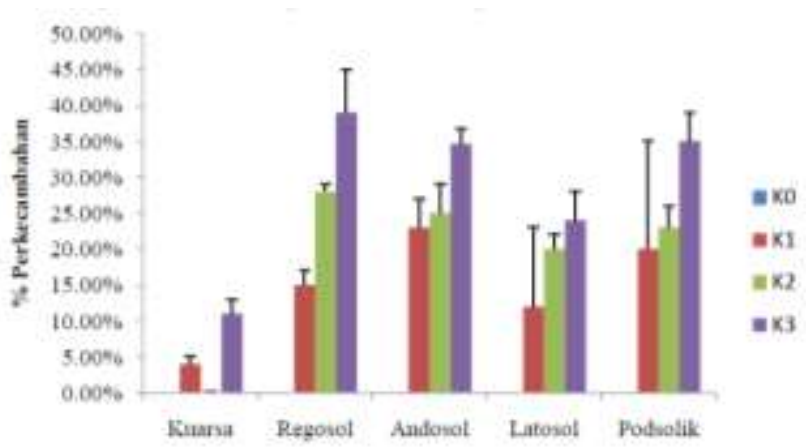

Gambar 2 . Persentase kecambah A. gangetica tidak normal pada berbagai konsentrasi teki terhadap berbagai jenis tanah

Aplikasi ekstrak teki dilakukan sebelum gulma tumbuh. Biasanya sistem olah tanah yang digunakan adalah sistem olah tanah sempurna (Sembodo 2010). Pada percobaan yang dilakukan oleh Wijaya et al. (2012) menunjukkan bahwa gulma berkecambah dalam waktu 2 minggu. Dengan demikian aplikasi ekstrak teki dapat dilakukan 2 minggu sebelum tanaman utama ditanam.

Terdapat kecenderungan bahwa meningkatnya konsentrasi ekstrak teki yang diberikan cenderung meningkatkan jumlah kecambah yang tidak normal semua jenis tanah,. Warna plumula yang menguning, terdapat karat pada plumula, ukuran radikula yang pendek dan ukuran kecambah yang pendek. Toksisitas menyebabkan terganggunya proses metabolisme sehingga daun klorosis dan akhirnya mengalami pertumbuhan yang tidak normal (Adnan et al. 2012). Selain itu, terdapat biji yang tidak tumbuh sehingga menyebabkan perkecambahan yang rendah. Biji yang tidak tumbuh tersebut menjadi berkerut, diduga karena efek allelopati dari $C$. rotundus.

\section{KESIMPULAN}

Seluruh formulasi biomassa yang diuji yaitu mulsa basah, mulsa kering, butiran dan tepung secara nyata efektif menekan perkecambahan biji A. gangetica 70\%-100\% dibandingkan dengan kontrol. Formulasi yang paling efektif digunakan adalah formulasi tepung. Pada berbagai jenis tanah yang diuji yaitu kuarsa, regosol, andosol, latosol dan podsolik sangat nyata mempengaruhi perkecambahan biji A. gangetica. Aplikasi ekstrak teki pada semua jenis tanah menunjukkan semakin tinggi konsentrasi ekstrak teki, maka semakin efektif menekan perkecambahan biji gulma A. gangetica. Pengaplikasian menggunakan konsentrasi sebesar
$1 \mathrm{~kg} \mathrm{~L}^{-1}$ sudah cukup untuk menekan perkecambahan biji gulma A. gangetica.

\section{DAFTAR PUSTAKA}

Adnan, Hasanudin, Manfarizah. 2012. Aplikasi beberapa dosis herbisida glifosat dan paraquat pada sistem tanpa olah tanah (tot) serta pengaruhnya terhadap sifat kimia tanah, karakteristik gulma dan hasil kedelai. J. Agrista 16(3): 135-145.

Anas I, Tampubolon JLO. 2004. Media campuran tanah - pasir dan pupuk anorganik untuk memproduksi inokulan cendawan mikoriza arbuskula (CMA). Bul. Agron 32 (1): 26-31.

Cahyani V.R. 2009. Pengaruh beberapa metode sterilisasi tanah terhadap status hara, populasi mikrobiota, potensi infeksi mikorisa dan pertumbuhan tanaman. $J$. Ilmu Tanah dan Agroklimatologi 6(10): 43-52.

Chozin MA, Delsi Y, Saputra R, Syarifi, Arifin SA, Zaman S. 2013. Study on allelophatic potential of Cyperus rotundus L. Di dalam : Baki HB, Denny K, Soekisman T, editor. Proceedings of $24^{\text {th }}$ AsianPasific Weed Science Society Conference; 2013 Oktober 22-25; Bandung, Indonesia. Bandung (ID): HIGI. hlm 353-360.

Cobb AH, Reade JPH. 2010. Herbicides and Plant Phyiology. Oxford: WileyBlackwell.

Delsi Y. 2012. Studi potensi allelopati teki (cyperus rotundus l.) sebagai herbisida untuk pengendalian gulma berdaun lebar. [Tesis]. Bogor (ID): Institut Pertanian Bogor.

Fitria Y. 2011. Pengaruh Alellopati gulma Cyperus rotundus, Ageratum conyzoides dan Digitaria adscendes terhadap pertumbuhan dan produksi tanaman tomat (Lycopersicon esculentum Mill). [Skripsi]. Bogor (ID): Institut Pertanian Bogor.

Hanafiah, Kemas A. 2007. Dasar-dasar Ilmu Tanah. Jakarta (ID): PT Raja Grafindo Persada. 
Hasibuan I, Prihanani, Sagala D. 2008. Pemanfaatan alelopati beberapa jenis gulma sebagai herbisida nabati dan dampaknya terhadap pertumbuhan dan hasil bawang merah. J. Agroqua 6(1): 18.doi: ISSN 0216-6585.

Inawati L. 2000. Pengaruh jenis gulma terhadap pertumbuhan, pembentukan bintil akar dan produksi tiga varietas kedelai (Glycine max (L) Merr). [Skripsi]. Bogor (ID): Institut Pertanian Bogor.

Iswandi A, Tampubolon JLO. 2004. Media campuran tanah-pasir dan pupuk anorganik untuk memproduksi inokulan mikoriza arbuskula (CMA). Bul. Agron 32(1).26-31.

Mubarok H. 2010. Studi pengelolaan gulma di Perkebunan Kelapa Sawit Sekunyir Estate PT Indotruda Tengah Minamas Plantation Kalimantan Tengah. [Skripsi]. Bogor (ID): Institut Pertanian Bogor.
Muktamar Z, Rahma T, Setyowati. 2003. Adsorpsi paraquat oleh bahan mineral ultisol dan entisol pada berbagai konsentrasi. JIPI 5(2): 40-47.

Saputra R. 2012. Pemanfaatan biomasa teki (Cyperus rotundus L.) untuk pengendalian gulma berdaun lebar pada pertanaman kedelai (Glycine $\max ($ L.) Merr.) [skripsi]. Bogor (ID): Institut Pertanian Bogor.

Sastroutomo, Soetikno S. 1990. Ekologi Gulma. Jakarta (ID): PT Gramedia Pustaka Utama.

Wardoyo SS, Haridjaja O, Widiatmaka. 2001. Distribusi herbisida glifosat di dalam tanah dan pengaruhnya terhadap ciri tanah serta pertumbuhan kedelai. JIPI 10(2).4045.

Wijaya B, Yudono P, Rogomulyo R. 2012. Uji efikasi herbisida pratumbuh untuk pengendalian gulma pertanaman tebu (Saccharum officinarum L.). Vegelatika 1(3).12-20. 